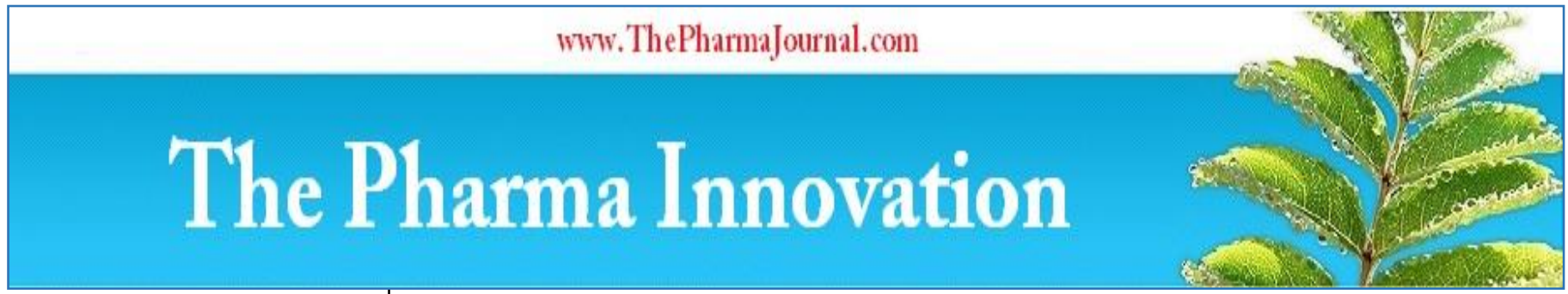

ISSN (E): 2277 - 7695

ISSN (P): 2349-8242

NAAS Rating: $\mathbf{5 . 0 3}$

TPI 2021; 10(2): 483-486

(C) 2021 TPI

www.thepharmajournal.com

Received: 13-12-2020

Accepted: 15-01-2020

\section{Manar W Jan}

Department of Molecular and Cellular Engineering, Sam

Higginbottom University of Agriculture, Technology and Sciences, Uttar Pradesh, India

\section{Jishnu Naskar}

Department of Molecular and Cellular Engineering, Sam

Higginbottom University of Agriculture, Technology and Sciences, Uttar Pradesh, India

Corresponding Author: Manar W Jan

Department of Molecular and Cellular Engineering, Sam Higginbottom University of Agriculture, Technology and Sciences, Uttar Pradesh, India

\title{
Assessment of phytochemical enhancement in Catharanthus roseus by silver nanoparticle
}

Manar W Jan and Jishnu Naskar

DOI: $\underline{\text { https://doi.org/10.22271/tpi.2021.v10.i2g.5709 }}$

\section{Abstract}

Catharanthus roseus (Madagascar periwinkle) is an ornamental plant belonging to the Apocynaceae family which is regarded as a rich source of pharmaceutically important terpenoid indole alkaloids (TIAs). Among these, vinblastine and vincristine are of particular importance because of their wide use in cancer chemotherapy. The present study deals with the preliminary phytochemical screening which reveals the presence of Alkaloids, Flavonoids, Carbohydrates, Saponins, Steroids, Glycosides, Phenols and Tannins in the aqueous extract of the leaf of Catharanthus roseus. The aim of this analysis is to see the significant increase in the amount of production of secondary metabolites in the leaves of Catharanthus roseus. The plant was exposed to silver nanoparticle in the concentration of $0.33 \mathrm{~g} / \mathrm{kg}$ of soil for three days, resulting in an increase in the amount of secondary metabolites. Qualitative analysis showed the maximum increase of carbohydrate from $(83.66$ to $261.1 \mathrm{mg} / \mathrm{ml}$ ) content and Saponins from $(8.78$ to $40.82 \mathrm{mg} / \mathrm{ml})$ after the application of silver nanoparticles. There was great amplification in alkaloids, phenol and steroid content from $(0.006$ to $0.187 \mathrm{mg} / \mathrm{ml}),(0.024$ to $0.115 \mathrm{mg} / \mathrm{ml})$ and $(4.85$ $\mathrm{mg} / \mathrm{ml}$ to $14.88 \mathrm{mg} / \mathrm{ml})$ respectively. Flavanoids content in nanoparticle applied extract of leaves $(0.681$ $\mathrm{mg} / \mathrm{ml})$ showed nearly six times higher concentration than the control plant $(0.187 \mathrm{mg} / \mathrm{ml})$. The overall study reveals that the nanoparticles play an important role in augmenting the quantity of secondary metabolites in the leaves and roots of Catharanthus roseus in a substantial manner.

Keywords: Catharanthus roseus, terpenoidindole alkaloids, secondary metabolites, phytochemical, nanoparticles

\section{Introduction}

Catharanthus roseus is a renowned medicinal plant, belonging to the family Apocynaceae and is a rich source of alkaloids, which are distributed in all parts of the plant. The leaves and roots are specialized for Monoterpenoids Indole Alkaloids (MIA) biosynthesis. It is known for the production of two potent anti-cancer agents, the bisindole alkaloids vincristine and vinblastine. These compounds are classified as terpeneindole alkaloids that are used as anti- cancer, antimalarial and anti-arrhythmic agents. Besides its ornamental usage, qualitative analysis of Catharanthus roseus plant confirms the presence of various phytochemicals like alkaloids, flavonoids, terpenoids, saponins, steroids, carbohydrates, anthaquinone glycosides etc in different extracts of its leaves and flowers. Vinblastine can have extensive use for the treatment of lung cancer, breast cancer, head and neck cancer, and testicular cancer ${ }^{[1]}$. The major monomeric alkaloid, vindoline and catharanthine are the biosynthetic precursors for the "dimeric" alkaloids, vinblastine and vincristine, two well-known anticancer drugs used in the treatment of acute leukemia and Hodgkin's disease ${ }^{[2]}$. The biosynthesis of these terpenoid indole alkaloids (TIAs) by the biosynthetic pathways in Catharanthus roseusis complex, multi-step and is under strict molecular regulation. Multiple enzymes and genes involved in the TIAs biosynthesis have been studied in recent decades. It has also been recently found that some regulatory proteins control the production of TIAs in C. roseus. Based on mastering the rough scheme of the pathway and cloning the related genes, metabolic engineering of TIAs biosynthesis has been studied in Catharanthus roseus aiming at increasing the desired secondary metabolites in the past few years. Metabolic engineering applications in TIAs pathway via over expression of these genes and regulators in Catharanthus roseus [3]. Nanotechnology provides an efficient technological platform for the study and transformation of flora system. Plants strongly interact with atmospheric and terrestrial environments and are expected to be effected by exposure of nanoparticles ${ }^{[4]}$. The effect of nanoparticles on production of these secondary phytochemicals with aim to potentially increase the natural

$$
\sim 483 \sim
$$


production of them in plants can bring a promising future. The silver nanoparticle enhances the anti-cancerous activity in Catharanthus roseus ${ }^{[5]}$.

\section{Materials and Methods}

Synthesis of silver nanoparticles: The silver nanoparticles were prepared by chemical reduction method ${ }^{[6]}$.

$1 \mathrm{ml}$ of silver nanoparticle solution was taken in an aluminium foil and was weighted. The solution was allowed to dry and again the weight was taken. The amount of silver nanoparticle was calculated in $100 \mathrm{ml}$ of solution. Characterization of silver nanoparticle was done using UV-Vis spectrophotometer, SEM and XRD

\section{Application of nanoparticle}

Application of silver NP was performed in the morning between 5 am-6am, because the temperature in the morning is moderate, facilitating the plants to absorb the nanoparticles. Nanoparticles were applied at $0.33 \mathrm{~g} / \mathrm{kg}$ of soil.

\section{Preparation of extract from leaves of Catharanthus roseus} Aqueous extract preparation: The leaves and roots of Catharanthus roseus were collected, washed, dried and powdered separately. $10 \mathrm{gms}$ of powdered leaves and roots were added to $100 \mathrm{ml}$ of distilled water. The aqueous extracts were heated and stirred at $70^{\circ} \mathrm{C}$ for 15 minutes and the mixtures were allowed to cool at room temperature. The extracts were filtered using filter paper followed by centrifugation at $10,000 \mathrm{rpm}$ at $10^{\circ} \mathrm{C}$ for 10 minutes. The supernatants were collected and stored in refrigerator for phytochemicals screening and analysis.

\section{Quantitative Analysis of Phytochemicals}

Test for alkaloids: The total alkaloid content was determined according to the method described ${ }^{[7]}$ by using atropine sulphate as a standard.

Test for carbohydrates: Total carbohydrate content was determined by using Anthrone as a standard. The absorbance of reaction mixture was measured at $750 \mathrm{~nm}$ against blank using spectrophotometer ${ }^{[7]}$

Test for flavanoids: Total flavanoids content was determined by aluminium chloride method using Quercetin as a standard.
The absorbance of reaction mixture was measured at $510 \mathrm{~nm}$ against blank using spectrophotometer ${ }^{[7]}$.

Test for saponins: Total saponin content was determined by using Vanilin as a standard. The absorbance of reaction mixture was measured at $544 \mathrm{~nm}$ against blank using spectrophotometer ${ }^{[7]}$.

Test for steroids: Total steroid content was determined by using Linalool as a standard. The absorbance of reaction mixture was measured at $750 \mathrm{~nm}$ against blank using spectrophotometer $^{[7]}$

Test for phenols: Total phenol content was determined by using catechol as a standard. The absorbance of reaction mixture was measured at $750 \mathrm{~nm}$ against blank using spectrophotometer ${ }^{[7]}$.

\section{Results and Discussion \\ Nanoparticle synthesis and characterization Silver nanoparticle}

Silver nanoparticles were prepared by reduction of silver nitrate solution by sodium borohydride in the presence of PEG which is working as a capping agent and a linker between nanoparticles and vinblastine. Silver nitrate and PEG is a colourless solution but after adding $\mathrm{NaBH}_{4}$ to the solution the colour turned to pale yellow which indicated formation of silver nanoparticles.

\section{Characterization of silver nanoparticles using UV-Vis spectroscopy}

Characterization of silver nanoparticle was done using UVVis Spectroscopy and the peak showed at 430nm which indicated total conversion of silver ions to silver nanoparticles.

\section{Scanning Electron Microscope (SEM) Image of Silver Nanoparticle}

Scanning electron microscopy (SEM) image of silver nanoparticles shows the morphology and size showing needle shaped particles. The size distribution of silver nanoparticle having length of approximately $2 \mu \mathrm{m}$ and width approximately $10-20 \mathrm{~nm}$ as shown in the figure 1 .

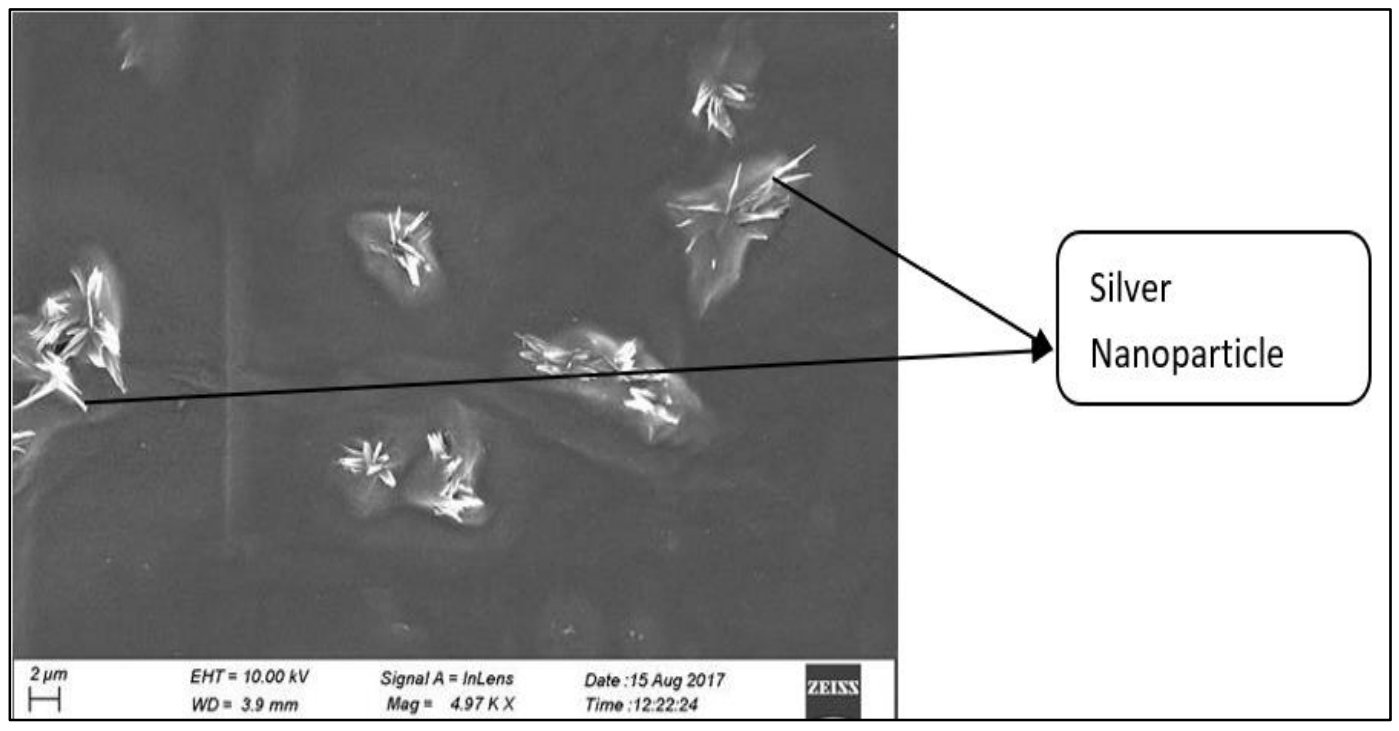

Fig 1: Scanning electron microscopy (SEM) image of Silver nanoparticles 


\section{Characterization of silver nanoparticle using XRD}

XRD analysis was carried out to confirm the crystalline nature of the particle as shown in figure 2. The Bragg's reflection observed an intense peak at $30^{\circ}$ which clearly indicated the presence of (2 20 ) set of lattice plane. The comparison XRD spectrum with the standard confirmed that the silver particles formed were in the form of nanocrystals. A bump is observed instead of a peak at $24^{0}$. The broad peak indicates that the silver nanoparticle is amorphous in nature.

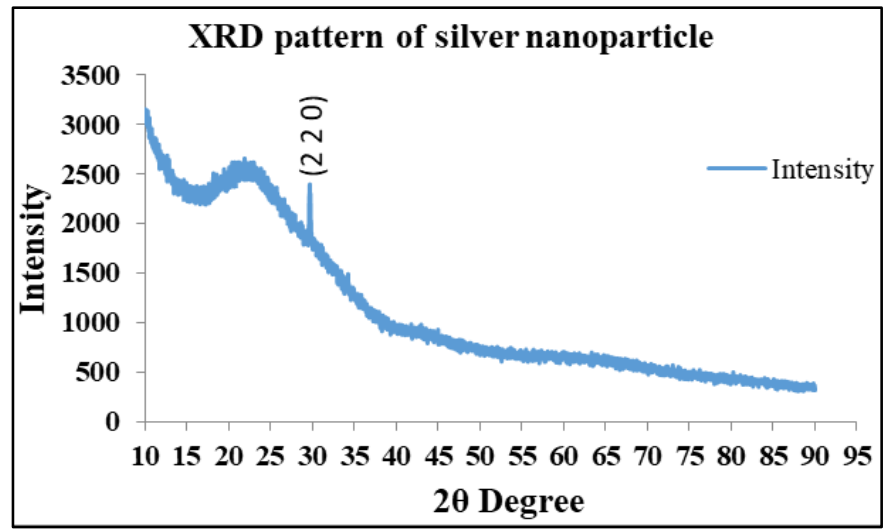

Fig 2: XRD pattern of silver nanoparticle

Physiological analysis of plants before and after exposure of silver nanoparticles

Comparative analysis of plant height:

The height of the plant was compared form the control plant as well as the plant supplemented with silver nanoparticle. The height of the plant supplemented with nanoparticle was increased from $53.66 \mathrm{~cm}$ to $57.1 \mathrm{~cm}$.

\section{Comparative analysis of leaf length:}

The length of the leaves was compared form the control plant and the plant supplemented with silver nanoparticle. The average length of the leaves of plants supplemented with nanoparticle was increased from $3.13 \mathrm{~cm}$ to $4.51 \mathrm{~cm}$.

Comparative analysis of root length:

The length of the root was compared form the control plant and the plant supplemented with silver nanoparticle. The average length of the roots of plants supplemented with nanoparticle was increased from $14.03 \mathrm{~cm}$ to $15.2 \mathrm{~cm}$.

\section{Quantitative analysis of phytochemicals}

The chemical group tests were performed and the results were shown in the table. Results indicated that alkaloid, carbohydrate, flavanoid, saponin, steroid, phenol and tannin were detected in aqueous and organic extract of leaves and roots of Catharanthus roseus.

Table 1: Quantitative analysis of phytochemicals before and after exposure of silver nanoparticles

\begin{tabular}{|c|c|c|}
\hline & $\begin{array}{c}\text { Control Plant } \\
(\mathbf{m g} / \mathbf{m l})\end{array}$ & $\begin{array}{c}\text { Silver NP Exposed Plant } \\
(\mathbf{m g} / \mathbf{m l})\end{array}$ \\
\hline Alkaloid & 0.006 & 0.188 \\
\hline Carbohydrate & 83.66 & 261.1 \\
\hline Flavanoid & 0.187 & 0.681 \\
\hline Saponin & 8.78 & 40.82 \\
\hline Steroid & 4.85 & 14.88 \\
\hline Phenol & 0.024 & 0.115 \\
\hline
\end{tabular}

The quantitative estimation of secondary metabolites before and after application of silver nanoparticles in the plant
(Table-1).

\section{Discussion}

Nanoparticles were prepared by chemical synthesis and its characterization was done using UV-VIS Spectroscopy, SEM and XRD analysis. Peaks were observed at $430 \mathrm{~nm}$ for silver nanoparticles. Scanning electron microscopy (SEM) image of silver nanoparticles shows the morphology and size of the particles. Needle shaped particles was seen in silver nanoparticles having size distribution of approximately $2 \mu \mathrm{m}$ in length and width approx 10-20 nm. X-Ray Diffraction analysis was carried out to confirm the crystalline nature of the nanoparticles. The Bragg's reflection observed a single intense peak at $30^{\circ}$ which clearly indicated that the silver particles formed were in the form of nanocrystals.

The aim of the current study was to increase the productivity of secondary metabolite. Administering of nanoparticle in the soil increased the concentration of alkaloids, carbohydrates, flavanoids, steroids, saponins and phenol after the exposure to silver nanoparticles in the aqueous extract of leaves.

The indole alkaloids vincristine and vinblastine has become important drug in the cancer chemotherapy because of their antitumor activity against various solid tumors and leukemias. These alkaloids are extracted commercially in massive quantities from Catharanthus roseus. Since, Catharanthus roseus contain less concentrations $(0.0005 \%)$, plant cell cultures can be used as an alternative way to enhance the production of these alkaloids ${ }^{[8]}$. Misawa et al found an efficiently feasible process for the production of catharanthine in the plants by cell fermentation and other chemical and enzymatic coupling reactions ${ }^{[9]}$. The significant influence of various compounds like vanadyl sulphate, abscisic acid and sodium chloride on catharanthine production has been described by ${ }^{[10]}$. Metabolic rate limitations through precursor feeding and the effect of elicitors on the biosynthesis of indole alkaloids in Catharanthus roseus through hairy root cultures was reported ${ }^{[11]}$

The effect of different concentrations of auxins and cytokinins on callus proliferation and total alkaloid content and 2,4Dichlorophenoxyacetic acid (2, 4-D) showed stimulatory effects on callus proliferation and total alkaloid content. Maximum callusing response $(76 \%)$ was illustrated at 4.0 $\mathrm{mg} / \mathrm{l}$ and the minimum (39\%) at $0.25 \mathrm{mg} / \mathrm{l}$. Of six concentrations of 2, 4-D used in MS media, $2.00 \mathrm{mg} / \mathrm{l}$ was better $(73 \%)$ for callus proliferation while $6 \mathrm{mg} / \mathrm{l}$ for increase in total leaf alkaloid content $(51 \%)$. It was seen that the higher concentration of 2, 4-D in media had an inhibitory effect on callus proliferation but stimulated a gradual increase in total alkaloid content. Fresh weight and total alkaloid level in leaf callus at different concentrations of 2, 4-D were significantly higher than for $0.25 \mathrm{mg} / 1$ 2, 4-D except for $0.50 \mathrm{mg} / \mathrm{l}$ and 1.00 $\mathrm{mg} / \mathrm{l}^{[12]}$. The coordinated induction of many genes including G10h by MeJA shows that strategies to improve TIA production using jasmonate-responsive transcription factors $[13,14]$

The biochemicaland metabolic engineering have been studied as a perspective for the creation of new cell lines producing TIAs in large scale bioreactors combined with efficient upstream and downstream processing ${ }^{[15]}$. Various elicitors of hydroxylase, peroxidase, acetyl transferase and inhibitors of oxygenase on regulation of vinblastine biosynthesis in cell suspension cultures of $C$. roseus showed Acetyl CoA, Hydrogen peroxide and Benzotriazole to be effective in improving the production of vinblastine ${ }^{[16]}$. 


\section{Conclusion}

This research was undertaken to analyze different phytochemicals in the leaves of Catharanthus roseus before and after exposure of silver nanoparticle. The phytochemical analysis revealed the presence of various phytochemicals like alkaloid, carbohydrate, flavanoid, saponin, steroid, phenol and tannin.

The quantitative analysis showed that there was a significant increase in the concentration of phytochemicals. There was great amplification in alkaloids (from 0.006 to $0.187 \mathrm{mg} / \mathrm{ml}$ ), phenol (from 0.024 to $0.115 \mathrm{mg} / \mathrm{ml}$ ) and steroids (from 4.85 $\mathrm{mg} / \mathrm{ml}$ to $14.88 \mathrm{mg} / \mathrm{ml}$ ) content after exposure silver nanoparticles. After the exposure of nanoparticle flavanoids content in extract of leaves $(0.681 \mathrm{mg} / \mathrm{ml})$ showed nearly six times higher concentration than the control plant $(0.187 \mathrm{mg} / \mathrm{ml})$. A great increase was shown in the carbohydrate (from 83.66 to $261.1 \mathrm{mg} / \mathrm{ml}$ ) content and Saponins from ( 8.78 to $40.82 \mathrm{mg} / \mathrm{ml}$ ) after the exposure.

Hence, from this study it can be concluded that nanoparticle exposure on the leaves of Catharanthus roseus prolifically enhances the production of secondary metabolites. This process is fissible and easy to perform than the other processes like cell culture, genetic modification and other lengthy processes. Further studies could also be conducted on the synthesis of other nanoparticles by different methods and exposure could be performed on various plants and a standard protocol could be crafted to obtain best results.

\section{References}

1. Aslam J, Khan SH, Siddiqui ZH, Fatima Z, Maqsood M, Bhat MA, et al. Catharanthus roseus (L.) G. Don. An important drug: its applications and production. Pharmacie Globale (IJCP) 2010;4:55-64.

2. Noble RL. The discovery of the Vinca Alkaloidschemotherapeutic agents against Cancer. Biochemistry and Cell Biology 1990;68:1344-1351.

3. Liu DH, Jin HB, Hui Chen HY, Cui LJ, Ren WW, Gong YF, et al. Terpenoid Indole Alkaloids Biosynthesis and Metabolic Engineering in Catharanthus roseus. Journal of Integrative Plant Biology 2007;49:961-974.

4. Navarro E, Baun A, Behra R, Hartmann NB, Filser J, Miao A et al. Environmental behaviour and ecotoxicity of engineered nanoparticles to algae, plants and fungi. Ecotoxicology 2008;17:372-386.

5. Askari M, Amirjani M, Saberi T. Evaluation of the effects of iron nanofertilizer on leaf growth, antioxidants and carbohydrates content of Catharanthus roseus. Journal of Plant Process and Function 2014;3:43-56.

6. Mazumdar H, Ahmed GU. Phytotoxicity effect of silver nanoparticles on Oryza sativa. International Journal of Chemtech Research 2011;3:1494-1500.

7. Devanaboyina N, Lakshmi R, Satyanarayana $P$, Sudeepthi K, Hemachakradhar N, Raju P, et al. Preliminary Phytochemical Screening, Quantitative Estimation and Evaluation Of Antimicrobial Activity of Alstoniamacrophylla Stem Bark. International Journal of Science Invention Today 2013;2:31-39.

8. Oksman-Caldentey KM, Inze D. Plant cell factories in the post Genomic era: new ways to Produce Designer Secondary Metabolites. Trends Plant Science 2004;9:433-440.

9. Misawa M, Endo T, Goodbody A, Vukovic J, Chapple C, Choi L, et al. Synthesis of dimeric Indole Alkaloids by
Cell free extracts from Cell Suspension Cultures of $C$. roseus. Phytochemistry 1988;27:1355-1359.

10. Smith JI, Smart NJ, Misawa M, Kurz WGW, Tallevi SG, DiCosmo F. Increased Accumulation of Indole Alkaloids by some Cell lines of Catharanthus roseus in response to addition of Vanadyl Sulphate. Plant Cell Reports 1987;6:142-145.

11. Morgan JA, Shanks JV. Determination of Metabolic ratelimitations by Precursor feeding in Catharanthus roseus hairy root Cultures, Journal of Biotechnology 2000;79:137-145.

12. Verma AK, Singh RR, Singh S. Improved alkaloid content in Callus Culture of Catharanthus roseus. Botanica Serbica 2012;36:123-130.

13. Menke FLH, Champion A, Kijne JW, Memelink J. A novel jasmonate- and elicitor-responsive element in the periwinkle secondary metabolite biosynthetic geneStr interacts with a jasmonate-and elicitor-inducible AP2-domain transcription factor, ORCA2. EMBO Journal 1999;18:4455-4463.

14. Memelink J, Verpoorte R, Kijne JW. ORCAnization of jasmonate-responsive gene expression in alkaloid metabolism. Trends Plant Science 2001;6:212-219.

15. Zhao J, Verpoorte R. Manipulating indole alkaloid production by Catharanthus roseus cell cultures in bioreactors: from biochemical processing to metabolic engineering. Phytochemistry Review 2007;6:435-457.

16. Guo ZG, Liu Y, Gong MZ, Chen W, Li WY. Regulation of vinblastine biosynthesis in cell suspension cultures of Catharanthus roseus. Plant Cell Tissue Organ Culture 2013;112:43-54. 